\title{
A matching law analysis of the reinforcing efficacy of wheel running in rats
}

\author{
TERRY W. BELKE and GENE M. HEYMAN \\ Harvard University, Cambridge, Massachusetts
}

\begin{abstract}
Previous research has demonstrated that running in a rotating wheel functions as a reinforcer for leverpressing in rats. In these studies, the pattern of responding was similar to the pattern of responding maintained by consummatory reinforcers, such as food and water. The present study investigated quantitative features of responding maintained by running. In previous experiments in which responses were reinforced according to variable-interval (VI) schedules and food and water served as the reinforcer, the equation for a rectangular hyperbola described the relationship between response rate and reinforcement rate. This experiment tested whether this quantitative regularity also applies to leverpressing maintained by the opportunity to run in a wheel. Fourteen male Wistar rats responded on levers for the opportunity to run. In each session, subjects were exposed to a series of VI schedules. An opportunity to run for $60 \mathrm{sec}$ was the reinforcing consequence. Results showed that response rate was a negatively accelerated function of reinforcement rate, and the relationship between these two variables was described well by the equation for a rectangular hyperbola. To further test the similarity between running and consummatory reinforcers, the response requirement and access were manipulated. In previous experiments with food and water, these types of manipulations differentially changed the two parameters of the hyperbola. A similar pattern of results was obtained with wheel running. Thus, the equation appears to apply to running about as well as it does to consummatory reinforcers.
\end{abstract}

Collier and Hirsch (1971) reasoned that "if running has the properties of a conventional reinforcer it should generate typical schedule effects" (p. 155). To test this idea, Collier and Hirsch exposed rats to a series of fixed-ratio reinforcement schedules with opportunity to run as the reinforcing consequence. The pattern of responding across the series of schedules was characteristic of that maintained by fixed-ratio schedules with food or water as the reinforcer. Recently, Iversen (1993) has demonstrated that running as a reinforcing consequence produces schedule effects typical of ratio and interval schedules of food reinforcement. The present study extended the investigation of the reinforcing properties of running. Previous research has shown that on variable-interval (VI) schedules, the relationship between response rate and reinforcement rate is described by the equation for a rectangular hyperbola. This experiment tested whether this quantitative model would apply when running was the reinforcer.

Herrnstein (1970) first proposed the application of a rectangular hyperbola model to describe a responsereinforcer relation. He used the notation:

$$
B_{1}=\frac{k R_{1}}{R_{1}+R_{\mathrm{e}}},
$$

The first author was supported by funding from the Alberta Heritage Scholarship Fund. Correspondence regarding this article should be directed to T. W. Belke, Department of Psychology, Biological Sciences Building, University of Alberta, Edmonton, AB, Canada T6G 2E9 (email: tbelke@cyber.psych.ualberta.ca). where $B_{1}$ is response rate, $R_{1}$ is reinforcement rate, and $k$ and $R_{\mathrm{e}}$ are fitted parameters. In experiments with food or water as the reinforcer, this equation typically accounts for about $90 \%$ of the variance in response rates (e.g., Williams, 1988), and the parameters, $k$ and $R_{\mathrm{e}}$, are differentially affected by experimental manipulations (Heyman \& Monaghan, 1987).

In the numerator, the parameter $k$ provides an estimate of the asymptotic response rate. In experiments, changes in the response requirement affected its magnitude. For example, the value of $k$ decreases when the response manipulandum is changed from a key to a treadle (McSweeney, 1978) or when the force required to make a response is increased (Heyman \& Monaghan, 1987). These results suggest that $k$ measures motoric components of reinforced behavior. In support of this idea, Porter and Villaneuva (1988) found that response duration was correlated with the value of $k$.

In the denominator, $R_{\mathrm{e}}$ is an estimate of the rate of reinforcement that maintains a one-half asymptotic response rate. For instance, inspection of Equation 1 shows that if the response rate is set to a value of $k / 2$, reinforcement rate $(R)$ must be equal to $R_{\mathrm{e}}$. In experiments, $R_{\mathrm{e}}$ has varied with changes in deprivation, reinforcer quality, and reinforcement magnitude (Bradshaw, Ruddle, \& Szabadi, 1981; Bradshaw, Szabadi, \& Bevan, 1978; Bradshaw, Szabadi, Ruddle, \& Pears, 1983; Conrad \& Sidman, 1956; Guttman, 1954; Hamilton, Stellar, \& Hart, 1985; Heyman \& Monaghan, 1987; Kraeling, 1961; de Villiers \& Herrnstein, 1976, analyzed results 
from studies prior to 1976). For example, the value of $R_{\mathrm{e}}$ decreases when the body weight of subjects responding for sucrose reinforcement is decreased (Bradshaw, Szabadi, et al., 1983) or when the concentration of sucrose reinforcement is increased (Heyman \& Monaghan, 1994). These results are consistent with the interpretation that $R_{\mathrm{e}}$ measures the efficacy of the reinforcer maintaining behavior.

Research on Equation 1 and related forms has been conducted under a wide range of conditions. For instance, the settings have been outside the laboratory (e.g., Baum, 1974) as well as in the laboratory; the subjects have been humans (see, e.g., Bradshaw, Szabadi, \& Bevan, 1976) as well as rats and pigeons; and the reinforcers have included money (Bradshaw et al., 1976) and brain stimulation (Hamilton et al., 1985) as well as food and water. However, to our knowledge, this is the first evaluation of Equation 1 in which the reinforcer has consisted of motor activity.

\section{METHOD}

\section{Subjects}

From an initial group of 21 male Wistar rats, 14 were selected on the basis of their running rates. These subjects were approximately 75 days old at the beginning of the experiment and were maintained at approximately $80 \%$ of their free-feeding body weights throughout the experiment.

\section{Apparatus}

The apparatus consisted of four running wheels in soundproof shells. Each wheel was $35.5 \mathrm{~cm}$ in diameter, and the front of each wheel was made of Plexiglas. A solenoid-operated brake was attached to the base of each wheel. When the solenoid was operated, a rubber tip attached to a metal shaft contacted the wheel and caused the wheel to stop gradually. A retractable lever was mounted at the opening of each wheel so that the lever would protrude into the wheel chamber when extended. A $24-\mathrm{V}$ dc light was mounted on each side of the frame of the wheel to illuminate the interior of the wheel and the area of the lever.

Control of experimental events and the recording of data were handled by Digital PDP-8A and PDP-11 computers in an adjacent room.

\section{Procedure}

Training and baseline. Initially, 21 rats were given free access to a running wheel for $30 \mathrm{~min}$ each day and the number of wheel revolutions was recorded. From this group of 21 rats, the 14 most active runners were selected as subjects. The subjects were then shaped to press a lever in a standard operant conditioning chamber. Each leverpress produced $0.1 \mathrm{ml}$ of $10 \%$ sucrose solution. When the subjects reliably pressed the lever, the schedule of reinforcement was shifted from a continuous reinforcement (CRF) schedule to a VI 10 -sec schedule.

Throughout the period of lever training, subjects continued to run in wheels for 30 -min sessions. When leverpressing for sucrose solution appeared stable, it was discontinued. At this time, the retractable lever in the wheel chamber was made operative and the opportunity to run for $60 \mathrm{sec}$ made contingent on a single leverpress. A session consisted of 50 opportunities to run.

Each session was then divided into five components with 10 reinforcements in each component. Between components, there was a 2-min time-out period. During this period, the wheel was braked, the lever was retracted, and the lights at the side of the wheel were extinguished.
Training the subjects to respond on VI schedules for running proceeded through the following steps. A CRF schedule was in effect in each component for 3 days; then the schedule in each component was changed to a variable-ratio five-response schedule. After 4 days, the schedule in each component was changed to a VI schedule. With the change from a response- to a time-based reinforcement requirement, the operation of the schedule was modified so that a reinforcement interval did not start elapsing until the first response was made. Thus, after the termination of a reinforcement, a new interval was selected but did not begin to elapse until the first leverpress.

The initial sequence of VI schedules for the five components was $15,7.5,5,7.5$, and $15 \mathrm{sec}$. Different discriminative stimuli were not present during the five components (see Heyman, 1992). Over the following 15 days, VI 30 -sec and VI 60 -sec schedules were introduced to arrive at the final sequence of VI schedules in the baseline condition: $60,15,5,7.5$, and $30 \mathrm{sec}$. The programmed interreinforcement intervals for the reinforcement schedules approximated an exponential distribution (Fleshler \& Hoffman, 1962). Leverpresses and time were recorded for each interval. Revolutions were counted for each reinforcement.

Performance during the baseline condition was judged stable when the following criteria were met. First, the $k$ and $R_{\mathrm{e}}$ values over the last 5 consecutive days could be neither the highest nor the lowest for the condition. Second, there could be no monotonic trend in the $k$ and $R_{\mathrm{e}}$ values over the last 3 days. Wilkinson's (1961) method of estimating the parameters of a hyperbolic function was used to generate $k$ and $R_{\mathrm{e}}$ values used for stability judgments. Criteria for stability were applied after 20 sessions, to allow time for response rates to differentiate across the different VI schedules.

Lever weight condition. Following the establishment of a stable baseline, a 26-g weight was attached to the retractable lever for 2 successive days. After this manipulation, subjects were returned to the baseline condition for 5 days.

Locked wheel condition. In the final treatment, subjects were placed in braked wheels for $45 \mathrm{~min}$ prior to the beginning of a session. During this braked wheel period, the wheel chamber was illuminated and the lever was retracted. This locked wheel condition was implemented for 2 successive days.

\section{RESULTS}

Figure 1 presents hyperbolic curves for the relationship between response and reinforcement rates and the associated $k$ and $R_{\mathrm{e}}$ values in the baseline condition for each subject. Response and reinforcement rates were averaged over the five sessions used in the judgment of stability. Asymptotic levels of responding $(k)$ ranged from 41 to 97 responses per minute, with a mean of 65 responses per minute. Estimates of $R_{\mathrm{e}}$ varied from 55 to 187 reinforcers per hour, with a mean of 99 reinforcers per hour. It is important to note that the metric in which $R_{\mathrm{e}}$ is given is the rate of wheel-running reinforcement per hour, excluding time spent running. In other words, the abscissa represents the rate of opportunities to run per hour not inclusive of consumption time. Finally, estimates of percentage of variance accounted for ranged from $78 \%$ to $99 \%$ with a mean value of $93 \%$.

Table 1 lists estimates of $k$ and $R_{\mathrm{e}}$, statistics, leverpresses, and wheel revolutions in the standard and added lever weight conditions. Response rates, reinforcement rates, leverpresses, and revolutions were averaged over the two sessions prior to the addition of the weight and over the two sessions with the weight on the lever. Rat 19 


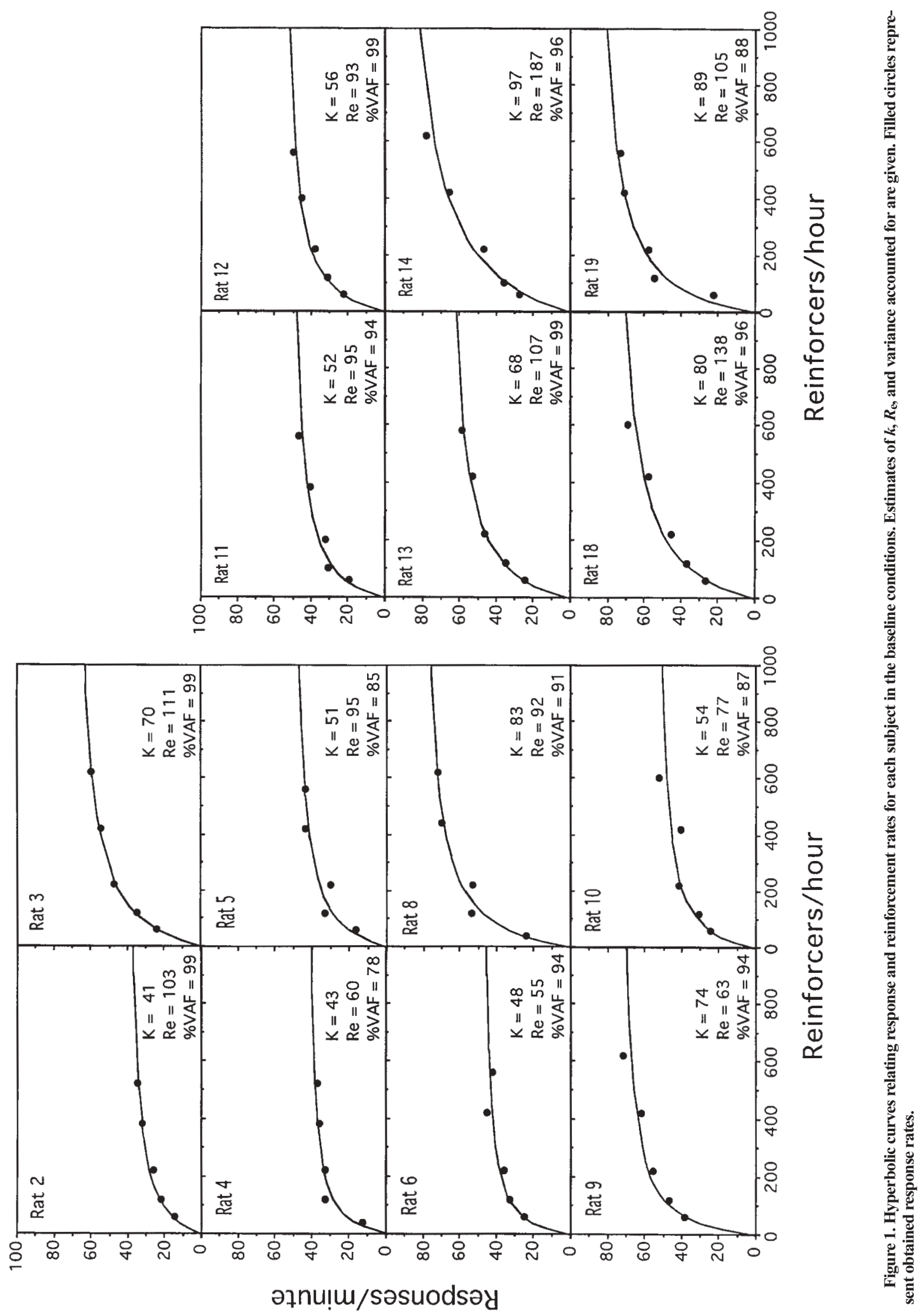


Table 1

$\boldsymbol{k}$ and $\boldsymbol{R}_{\mathrm{e}}$ Estimates, Standard Error Values, Variance Accounted for, Leverpresses, and Revolutions for the Standard Lever and Standard Lever Plus 26 g Weight Conditions for Each Subject

\begin{tabular}{|c|c|c|c|c|c|c|c|}
\hline Rat & $k$ & $R_{\mathrm{e}}$ & $S E(k)$ & $S E\left(R_{\mathrm{e}}\right)$ & $\% \mathrm{VAF}$ & Presses & Revolutions \\
\hline \multicolumn{8}{|c|}{ Standard Lever Weight } \\
\hline 2 & 43 & 108 & 3.8 & 28.8 & 94.7 & 436 & 1,309 \\
\hline 3 & 48 & 53 & 3.9 & 20.2 & 87.0 & 642 & 1,946 \\
\hline 4 & 72 & 57 & 6.2 & 16.4 & 83.5 & 900 & 2,037 \\
\hline 5 & 75 & 50 & 8.3 & 17.9 & 67.2 & 912 & 1,867 \\
\hline 6 & 45 & 68 & 1.0 & 6.0 & 99.1 & 554 & 1,274 \\
\hline 8 & 78 & 104 & 7.1 & 28.3 & 92.2 & 783 & 1,978 \\
\hline 9 & 43 & 26 & 2.8 & 11.2 & 72.2 & 705 & 2,013 \\
\hline 10 & 64 & 96 & 6.3 & 32.9 & 90.6 & 693 & 1,755 \\
\hline 11 & 53 & 112 & 5.4 & 28.9 & 91.2 & 485 & 1,345 \\
\hline 12 & 50 & 74 & 3.4 & 19.5 & 93.3 & 608 & 2,107 \\
\hline 13 & 59 & 94 & 4.5 & 23.8 & 93.4 & 657 & 1,506 \\
\hline 14 & 77 & 183 & 9.0 & 55.9 & 96.0 & 650 & 1,473 \\
\hline 18 & 90 & 186 & 8.0 & 42.5 & 97.1 & 708 & 1,625 \\
\hline$M$ & 61 & 93 & & & 89.0 & 672 & 1,710 \\
\hline \multicolumn{8}{|c|}{ Standard Lever Weight Plus $26 \mathrm{~g}$} \\
\hline 2 & 37 & 226 & 5.9 & 77.1 & 94.1 & 296 & 1,348 \\
\hline 3 & 36 & 60 & 4.7 & 34.2 & 75.3 & 483 & 1,984 \\
\hline 4 & 44 & 38 & 4.6 & 13.7 & 61.9 & 609 & 2,076 \\
\hline 5 & 42 & 35 & 5.4 & 15.5 & 47.8 & 551 & 1,880 \\
\hline 6 & 25 & 73 & 8.8 & 98.2 & 48.7 & 340 & 1,048 \\
\hline 8 & 50 & 87 & 6.1 & 30.4 & 85.6 & 541 & 1,916 \\
\hline 9 & 18 & 12 & 1.3 & 9.9 & 39.1 & 370 & 1,930 \\
\hline 10 & 33 & 45 & 1.8 & 11.6 & 91.5 & 493 & 1,710 \\
\hline 11 & 34 & 93 & 3.0 & 23.7 & 92.5 & 371 & 1,679 \\
\hline 12 & 35 & 137 & 6.1 & 65.1 & 88.2 & 348 & 2,009 \\
\hline 13 & 35 & 82 & 3.0 & 24.4 & 92.0 & 421 & 1,517 \\
\hline 14 & 50 & 187 & 3.3 & 29.6 & 98.5 & 416 & 1,654 \\
\hline 18 & 45 & 117 & 8.2 & 60.1 & 77.8 & 454 & 1,603 \\
\hline$M$ & 37 & 92 & & & 76.4 & 438 & 1,720 \\
\hline
\end{tabular}

Note-Rat 19 failed to complete sessions.

failed to complete the sessions during which the weight was added to the lever. Table 1 shows that the remaining 13 subjects had a lower value of $k$ in the added weight condition. Figure 2 shows changes in the average values of $k$ and $R_{\mathrm{e}}$ when the weight was added to the lever. Average values of $k$ in the standard and added weight conditions were 61 and 37 responses per minute, while the average values of $R_{\mathrm{e}}$ were 93 and 92 reinforcers per hour. Thus, the asymptotic level of responding decreased by 24 responses per minute $(t=8.67, p<.001)$ while $R_{\mathrm{e}}$ remained unchanged $(t=0.11, p=.91)$.

Figure 3 shows the average number of leverpresses and revolutions in the standard and added weight conditions. Average leverpresses in these two conditions were 672 and 438, respectively. Table 1 shows that all subjects pressed the lever less when the force requirement was increased. In contrast, average revolutions for the two conditions were 1,710 and 1,720, respectively. Thus, increasing the force required for an effective response decreased the instrumental behavior $(t=11.81, p<$ $.001)$, while the consequential behavior remained unchanged $(t=0.24, p=.81)$.

Figure 4 shows mean revolutions across components in the standard and added weight conditions. In both conditions, average revolutions increased throughout the session. For the standard lever weight condition, the mean number of revolutions increased by 101 revolutions from 284 in the first component to 385 in the last component. For the added weight condition, mean revolutions increased by 92 revolutions from 290 in the first

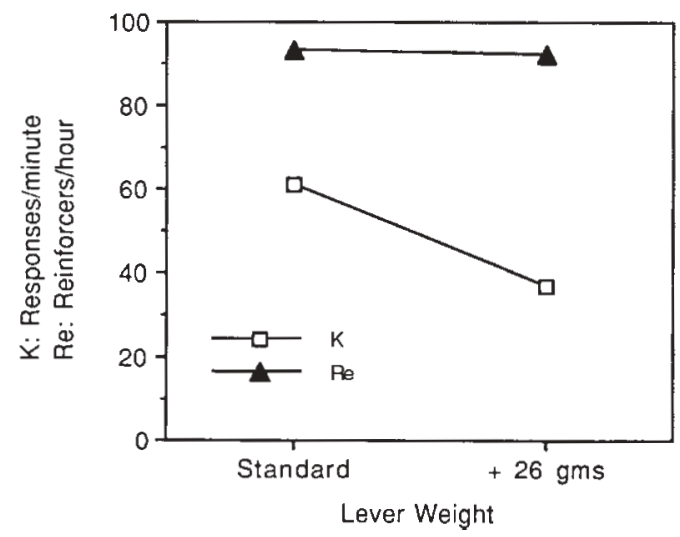

Figure 2. Average $k$ and $\boldsymbol{R}_{\mathrm{e}}$ estimates in the standard lever weight and standard lever weight plus $26 \mathrm{~g}$ conditions. 
component to 382 in the last component. Recall that the duration of opportunities to run was equivalent across components; therefore, these increases in revolutions represent increases in running rate. Paired $t$ test comparisons revealed that for both conditions, the increases in revolutions were significant $(t=5.0, p<.001 ; t=$ $6.0, p<.001)$.

Table 2 lists estimates of $k$ and $R_{\mathrm{e}}$, statistics, leverpresses, and wheel revolutions for each subject in the baseline and locked wheel conditions. Response rates, reinforcement rates, leverpresses, and revolutions were averaged over the two sessions prior to the locked wheel condition and over the two sessions of the locked wheel condition. Inspection of Table 2 shows that in 11 out of 14 subjects, values of $R_{\mathrm{e}}$ were lower in the locked wheel condition. Figure 5 shows the average values of $k$ and $R_{\mathrm{e}}$ in the baseline and locked wheel conditions. In both conditions, the average value of $k$ was 57 responses per minute. In contrast, the average values of $R_{\mathrm{e}}$ in the baseline and locked wheel conditions were 73 and 51 rein-

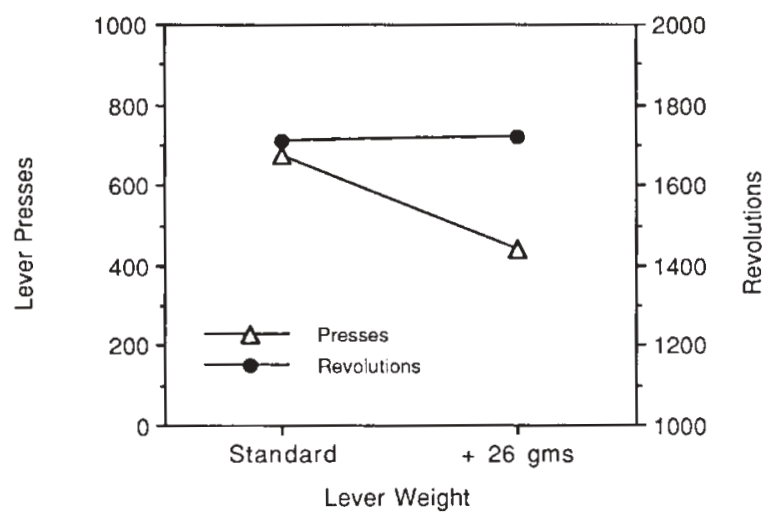

Figure 3. Average leverpresses and revolutions per session in the standard lever weight and standard lever weight plus $26 \mathrm{~g}$ conditions.

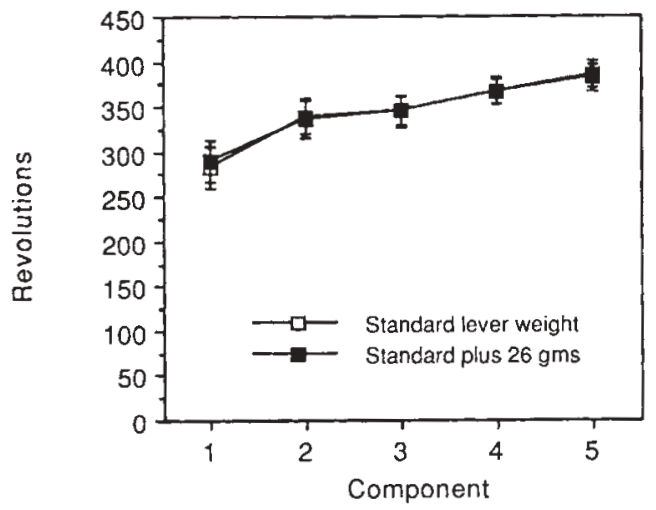

Figure 4. Average revolutions per component in the standard lever weight and standard lever weight plus $26 \mathrm{~g}$ conditions.

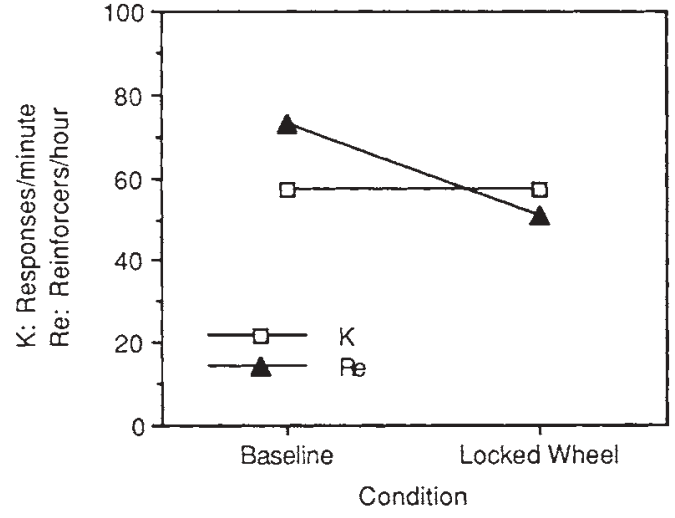

Figure 5. Average $k$ and $R_{\mathrm{e}}$ estimates in the baseline and locked wheel conditions.

forcers per hour, respectively. Thus, further restriction of activity level increased motivation for wheel running as indexed by the decline in $R_{\mathrm{e}}(t=2.59, p<.05)$, while the asymptotic level of responding $(k)$ remained unchanged $(t=0.10, p=.93)$.

Average leverpresses and revolutions in the baseline and locked wheel conditions are presented in Figure 6. The average number of presses in these two conditions were 685 and 797, respectively. Table 2 shows that leverpresses were higher in the locked wheel condition for all but 1 subject. Average revolutions for the two conditions were 1,611 and 1,803, respectively. As before, all subjects, save one, showed increased running in the locked wheel condition. Thus, further restriction of activity increased both the instrumental behavior $(t=4.69, p<$ $.001)$ and the consequential behavior $(t=3.29, p<.01)$.

Figure 7 shows mean revolutions across components in the baseline and locked wheel conditions. In the baseline condition, mean revolutions increased by 102 revolutions from 269 in the first component to 371 in the last component. In the locked wheel condition, mean revolutions increased by 47 revolutions from 334 in the first component to 381 in the last component. Within each condition, increases in revolutions from the first to the last component were significant $(t=5.7, p<.001 ; t=$ $2.7, p<.05)$. Between conditions, the locked wheel manipulation increased revolutions over baseline levels in the early (e.g., first component, $t=3.4, p<.01$ ), but not the later components.

\section{DISCUSSION}

The results from the present study extend the application of Equation 1 to the study of the reinforcing properties of wheel running in rats. When the opportunity to run was arranged on different VI schedules of reinforcement, the response rates were a negatively accelerated monotonic function of the obtained rates of reinforcement. The relationship between response and reinforcement 
Table 2

$\boldsymbol{k}$ and $\boldsymbol{R}_{\mathrm{e}}$ Estimates, Standard Error Values, Variance Accounted for, Leverpresses, and Revolutions for the Baseline and Locked Wheel Conditions for Each Subject

\begin{tabular}{|c|c|c|c|c|c|c|c|}
\hline Rat & $k$ & $R_{\mathrm{e}}$ & $S E(k)$ & $S E\left(R_{\mathrm{e}}\right)$ & $\%$ VAF & Presses & Revolutions \\
\hline \multicolumn{8}{|c|}{ Baseline } \\
\hline 2 & 36 & 62 & 3.1 & 20.2 & 89.2 & 479 & 1,174 \\
\hline 3 & 45 & 46 & 2.2 & 10.8 & 93.2 & 631 & 1,822 \\
\hline 4 & 63 & 44 & 5.6 & 16.1 & 76.2 & 863 & 1,986 \\
\hline 5 & 104 & 83 & 8.4 & 23.8 & 91.3 & 1,133 & 1,856 \\
\hline 6 & 38 & 68 & 6.4 & 52.0 & 74.3 & 469 & 1,064 \\
\hline 8 & 82 & 115 & 5.5 & 24.5 & 96.2 & 813 & 1,254 \\
\hline 9 & 46 & 29 & 9.3 & 39.8 & 22.0 & 760 & 1,951 \\
\hline 10 & 51 & 63 & 9.1 & 51.4 & 65.3 & 660 & 1,663 \\
\hline 11 & 55 & 99 & 5.2 & 29.9 & 91.6 & 589 & 1,633 \\
\hline 12 & 45 & 73 & 1.0 & 6.2 & 99.2 & 546 & 2,034 \\
\hline 13 & 65 & 132 & 8.9 & 50.6 & 87.0 & 647 & 1,384 \\
\hline 14 & 49 & 46 & 3.0 & 13.0 & 92.2 & 709 & 1,731 \\
\hline 18 & 68 & 89 & 4.5 & 20.1 & 94.9 & 749 & 1,688 \\
\hline 19 & 50 & 71 & 9.3 & 33.0 & 71.5 & 573 & 1,312 \\
\hline$M$ & 57 & 73 & & & 81.7 & 685 & 1,611 \\
\hline \multicolumn{8}{|c|}{ Locked Wheel } \\
\hline 2 & 41 & 58 & 1.7 & 10.2 & 96.2 & 548 & 1,340 \\
\hline 3 & 45 & 39 & 3.3 & 14.6 & 79.9 & 688 & 1,935 \\
\hline 4 & 59 & 22 & 2.9 & 8.1 & 79.4 & 979 & 2,170 \\
\hline 5 & 91 & 62 & 4.0 & 12.0 & 96.0 & 1,119 & 1,909 \\
\hline 6 & 34 & 25 & 2.4 & 12.1 & 67.0 & 581 & 1,285 \\
\hline 8 & 68 & 38 & 3.4 & 10.3 & 89.4 & 1,000 & 2,128 \\
\hline 9 & 46 & 8 & 3.8 & 11.0 & 17.2 & 876 & 2,074 \\
\hline 10 & 42 & 11 & 4.5 & 16.1 & 23.1 & 795 & 1,771 \\
\hline 11 & 38 & 25 & 5.3 & 25.5 & 37.4 & 634 & 1,634 \\
\hline 12 & 48 & 95 & 11.8 & 70.5 & 54.2 & 594 & 2,182 \\
\hline 13 & 84 & 154 & 5.0 & 25.7 & 97.9 & 733 & 1,402 \\
\hline 14 & 49 & 27 & 7.0 & 26.9 & 33.4 & 815 & 1,851 \\
\hline 18 & 84 & 107 & 1.0 & 4.2 & 99.8 & 860 & 1,849 \\
\hline 19 & 64 & 41 & 7.1 & 25.0 & 73.4 & 938 & 1,713 \\
\hline$M$ & 57 & 51 & & & 67.5 & 797 & 1,803 \\
\hline
\end{tabular}

rates across a series of VI schedules was described well by the hyperbolic matching equation.

The interpretation of the $k$ parameter in the equation as an index of the motor component of a reinforced response was supported by altering the force required to make a response. Previous studies (Bradshaw, Szabadi, \& Ruddle, 1983; Hamilton et al., 1985; Heyman \& Monaghan, 1987) have shown that manipulating the force required to make a response by varying lever weight decreases the value of $k$ while $R_{\mathrm{e}}$ remains relatively stable. Food, brain stimulation, and water functioned as reinforcers in these studies. The results of the present study are consistent with previous findings. Increasing the force required to make a response produced a systematic decline in the value of $k$ while the value of $R_{\mathrm{e}}$ showed no systematic change. This finding supports the interpretation of the $k$ parameter as an index of a motoric component of a response reinforced by the opportunity to run.

The interpretation of the $R_{\mathrm{e}}$ parameter in the hyperbolic matching equation as an index of the motivation component of a reinforced response was supported by restricting activity within the context of the wheel. This manipulation was based on observations that running varies with restriction of the opportunity to run (Hill,
1956; Premack \& Schaeffer, 1963). Previous studies (Bradshaw et al., 1981; Bradshaw et al., 1978; Bradshaw, Szabadi, et al., 1983; Conrad \& Sidman, 1956; Guttman, 1954; Hamilton et al., 1985; Heyman \& Monaghan, 1987; Kraeling, 1961; de Villiers \& Herrnstein, 1976, analyzed results from studies prior to 1976) have shown that manipulations that alter reinforcer quality, reinforcer magnitude, or deprivation level produce changes in the $R_{\mathrm{e}}$ parameter while $k$ remains relatively stable. Similarly, withholding opportunity to run within the context of the wheel in the present study produced a decline in $R_{\mathrm{e}}$ while the value of $k$ remained unchanged. An interpretation of this finding would be that this operation increased the motivation to run, which was reflected by an increase in the motivational component of the reinforced response. Thus, the reinforcing efficacy of running was increased.

Furthermore, changes in the instrumental and contingent behaviors agree with these interpretations. In a reinforcement relation, the instrumental and contingent behaviors frequently covary. As the contingent behavior increases, the instrumental behavior increases; as the contingent behavior decreases, the instrumental behavior decreases. This covariance captures a motivational 


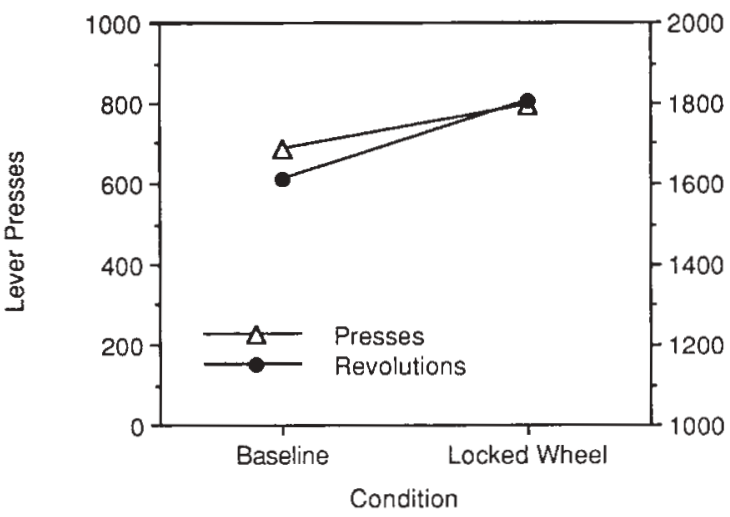

Figure 6. Average leverpresses and revolutions per session in the baseline and locked wheel conditions.

relation between an instrumental behavior and a contingent behavior (Bolles, 1967). For example, increasing motivation to run in the present study, by restricting activity prior to the session, increased running as well as the leverpressing that it was contingent upon. However, these behaviors need not always covary. For example, the manipulation of the force requirement for leverpressing affected leverpressing without affecting running. As such, the motoric aspect of reinforced responding was affected independently of the motivational component.

Finally, an analysis of the within-session changes in revolutions showed that running increased throughout the course of a session. The more subjects ran, the faster subjects ran. If running is a consummatory behavior and revolutions can be considered a unit of consumption, these data suggest that there was no satiation effect with consumption over the session. With other reinforcers such as food or water, consumption typically produces satiation. Running, unlike food and water, does not involve the ingestion of a substance that produces satiety. In this respect, running is similar to electrical brain stimulation (Olds \& Milner, 1954).

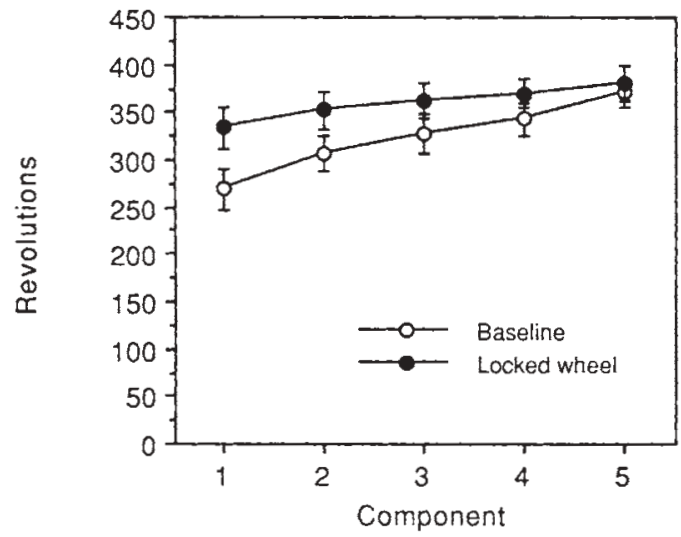

Figure 7. Average revolutions per component in the baseline and locked wheel conditions.
Furthermore, the relationship between this increasing running rate within a session and changes in the reinforcing efficacy of running remains open to question. If motivation to run increased throughout the session, $R_{\mathrm{e}}$ should have decreased. A decline in $R_{\mathrm{e}}$ across the session would produce systematic deviations of obtained from predicted response rates. Specifically, response rates should have been overestimated at the beginning of the session and underestimated at the end. However, the plots of the hyperbolic functions do not show any systematic deviations of obtained response rates from predicted response rates for the two leanest schedules.

In general, the results show both similarities and differences between running and other consummatory behaviors. Like eating and drinking, when running functions as a reinforcing consequence, the responsereinforcer relation is well described by the equation for a rectangular hyperbola. However, unlike eating and drinking, running does not appear to satiate with consumption. Furthermore, if this pattern of increased running throughout the session is mirrored by increases in response rates, the within-session pattern of responding may differ from the bitonic pattern observed for consummatory reinforcement (McSweeney \& Hinson, 1992).

\section{REFERENCES}

Baum, W. M. (1974). Choice in free-ranging wild pigeons. Science, 185, 78-79.

Bolles, R. C. (1967). Theory of motivation. New York: Harper \& Row. Bradshaw, C. M., Ruddle, H. V., \& Szabadi, E. (1981). Relationship between response rate and reinforcement frequency in variableinterval schedules: II. Effect of the volume of sucrose reinforcement Journal of the Experimental Analysis of Behavior, 35, 263-269.

Bradshaw, C. M., Szabadi, E., \& Bevan, P. (1976). Behavior of humans in variable interval schedules of reinforcement. Journal of the Experimental Analysis of Behavior, 26, 135-141.

Bradshaw, C. M., Szabadi, E., \& Bevan, P. (1978). Relationship between response rate and reinforcement frequency in variable interval schedules: The effect of the concentration of sucrose reinforcement. Journal of the Experimental Analysis of Behavior, 29, 447-452.

Bradshaw, C. M., Szabadi, E., \& Ruddle, H. V. (1983). Herrnstein's equation: Effect of response force requirement on performance in variable-interval schedules. Behavior Analysis Letters, 3, 93-100.

Bradshaw, C. M., Szabadi, E., Ruddle, H. V., \& Pears, E. (1983). Herrnstein's equation: Effect of deprivation level on performance in variable-interval schedule. Behavior Analysis Letters, 3, 267-273.

Collier, G. H., \& Hirsch, E. (1971). Reinforcing properties of spontaneous activity in the rat. Journal of Comparative \& Physiological Psychology, 77, 155-160.

Conrad, D. G., \& Sidman, M. (1956). Sucrose concentration as reinforcement for lever pressing by monkeys. Psychological Reports, 2, 381-384.

de Villiers, P. A., \& Herrnstein, R. J. (1976). Toward a law of response strength. Psychological Bulletin, 83, 1131-1153.

FleshleR, M., \& HofFMAN, H. S. (1962). A progression for generating variable interval schedules. Journal of the Experimental Analysis of Behavior, 5, 529-530.

GutTMAn, N. (1954). Equal reinforcement values for sucrose and glucose solutions compared with equal-sweetness values. Journal of Comparative \& Physiological Psychology, 47, 358-361.

Hamilton, A. L., Stellar, J. R., \& Hart, E. B. (1985). Reward, performance, and the response strength method in self-stimulating rats: Validation and neuroleptics. Physiology \& Behavior, 35, 897-904 
HerRnsteIn, R. J. (1970). On the law of effect. Journal of the Experimental Analysis of Behavior, 13, 243-266.

Heyman, G. M. (1992). The effects of methylphenidate on response rate and measures of motor performance and reinforcement efficacy. Psychopharmacology, 109, 145-152.

Heyman, G. M., \& Monaghan, M. M. (1987). Effects of changes in response requirement and deprivation on the parameters of the matching law equation: New data and review. Journal of Experimental Psychology: Animal Behavior Processes, 13, 384-394.

Heyman, G. M., \& Monaghan, M. M. (1994). Reinforcer magnitude and the matching (sucrose concentration) law theory of response strength. Journal of the Experimental Analysis of Behavior, 61, 505-516.

Hill, W. F. (1956). Activity as an autonomous drive. Journal of Comparative \& Physiological Psychology, 49, 15-19.

IVERSEN, I. H. (1993). Techniques for establishing schedules with wheel running as reinforcement in rats. Journal of the Experimental Analysis of Behavior, 60, 219-238.

KraELing, D. (1961). Analysis of amount of reward as a variable in learning. Journal of Comparative \& Physiological Psychology, 54, 560-565.

McSweeney, F. K. (1978). Prediction of concurrent keypeck treadlepress responding from simple schedule performance. Animal Learning \& Behavior, 6, 444-450.
McSweeney, F. K., \& Hinson, J. M. (1992). Patterns of responding within sessions. Journal of the Experimental Analysis of Behavior, 58, 19-36.

Olds, J., \& Milner, P. (1954). Positive reinforcement produced by electrical stimulation of septal area and other regions of rat brain. Journal of Comparative \& Physiological Psychology, 47, 419-427.

Porter, J. H., \& Villanueva, H. F. (1988). Assessment of pimozide's motor and hedonic effects on operant behavior in rats. Pharmacology, Biochemistry \& Behavior, 31, 779-786.

Premack, D., \& Schaeffer, R. W. (1963). Some parameters affecting the distributional properties of operant-level running in rats. Journal of the Experimental Analysis of Behavior, 6, 473-475.

Wilkinson, G. N. (1961). Statistical estimation in enzyme kinetics. Biochemical Journal, 80, 324-332.

Williams, B. A. (1988). Reinforcement, choice, and response strength. In R. C. Atkinson, R. J. Herrnstein, G. Lindzey, \& R. D. Luce (Eds.), Stevens' handbook of experimental psychology, 2nd ed. (Vol. 2, pp. 167-244). New York: Wiley Interscience.

(Manuscript received May 10, 1993; revision acccepted for publication December $15,1993$. 